\title{
Knowledge, Attitude and Practices of Osteoporosis Risk Factors among Jazan University Students, 2019
}

\author{
Zenat A. Khired ${ }^{1}$, Manal AlHulaibi ${ }^{2}$, Alhasan Alhazmi ${ }^{2}$, Amjad Durayb ${ }^{2}$, Rawiah Mushari ${ }^{2}$, \\ Sarah Mahzari ${ }^{2}$, Wafa kilani ${ }^{2}$, Amani Jawhari ${ }^{2}$, Rawan Alhazmi ${ }^{2}$, Elmahdy. M.H ${ }^{3}$ \\ ${ }^{1}$ Assistant Professor, Department of Surgery, Faculty of Medicine, Jazan University, Saudi Arabia \\ ${ }^{2}$ Medical Student, Jazan University, Saudi Arabia \\ ${ }^{3}$ Professor of Public Health and Preventive Medicine Jazan University, Faculty of Medicine, Saudi Arabia
}

*Corresponding author: Zenat A. Khired, MD; https://orcid.org/0000-0002-8728-5381;

zkherd@jazanu.edu.sa; zask_2010@yahoo.com

Received 15 December 2021;

Accepted 03 January 2021;

Published 05 January 2022

\begin{abstract}
Osteoporosis is one of the non-communicable diseases that closely links to lifestyle and nutrition. This is a cross-sectional descriptive epidemiologic study, carried out on 440 Jazan university students (males\& females). They are chosen by a stratified multistage cluster sampling technique to assess their knowledge, attitude, and practices (KAP) about osteoporosis risk factors. The data are collected using a validated semi structured Arabic questionnaires.

The findings revealed that almost all survey participants agreed with the definition of osteoporosis, which is the decrease of bone density, with only $8.7 \%$ disagreeing. Furthermore, 80.0 percent of survey participants classified osteoporosis as a cause of bone fracture.

The findings suggest that the study participants' good attitudes toward risk factor prevention of osteoporosis are linked to the daily consumption of an acceptable amount of milk. Another positive attitude toward osteoporosis prevention stemmed from a reduction in the amount of energy drinks consumed, which has been identified as an osteoporosis risk factor. The study recommends that university students of all grades participate in health education programs about osteoporosis risk factors and preventive treatment.
\end{abstract}

Keywords: knowledge, attitude, practices, osteoporosis, and risk factors

\section{Introduction}

Osteoporosis remains a global health problem associated with significant morbidity, mortality, and health care costs, it has been considered as the second most important health concern following heart diseases in developed countries (Sozen et al., 2017).

Osteoporosis is a silent disease of structural deterioration of bone tissues. It develops slowly over several years, that might not be diagnosed except after bone fractures due to minor trauma. An analytical study showed that $34 \%, 30 \%$ of healthy Saudi women and men, respectively, aged 50 to 79 years old are osteoporotic (Sadat-Ali et al., 2012).

The most common injuries in people with osteoporosis are wrist, hip, spinal, bone (vertebrae) fractures. It is usually not painful until a fracture occurs, but spinal fractures are a "a "Common cause of (chronic) long - term pain (Dequeker, 1997). Some people are at higher risk for bone fractures than others.

Bones in early adult life are at their thickest and strongest, and their density increases until the late twenties, then they start losing bone density gradually from around 35 years of age. This happens to all, but some people are much faster than normal. That means that they are at higher risk of fracture (WHO, 2007).

Body hormones can affect bone turnover processes, a patient may have a higher risk of developing osteoporosis- related conditions that may cause osteoporosis include: hyperthyroidism, adrenal gland disorders, such as the syndrome of Cushing reduced sex hormone levels (estrogen and testosterone), hyper parathyroid and pituitary gland disorders (parathyroid gland overactivity) (Dequeker, 1997).

Other factors that are considered to increase the risk of osteoporosis and broken bones include: a family history of osteoporosis, parental history of hip fracture, an index of 19 or less body mass (BMI) (Asomaning, Bertone-Johnson, et al., 2006).

Long term use of high dose oral corticosteroids, eating disorders such as anorexia or bulimia (Asomaning, Bertonejohnson, et al., 2006; Pouresmaeili et al., 2018)

Problems with malabsorption, such as coeliac disease and Crohn's disease, some medicines used to treat breast cancer and prostate cancer that affect hormone levels during long inactivity periods such as a long term of immobilization (Asomaning, Bertone-Johnson, et al., 2006; Pouresmaeili et al., 2018) 
Screening Tests Central DEXA is the most commonly used bone measurement test used for osteoporosis screening; other screening tests include peripheral DEXA and quantitative ultrasound (QUS) to diagnose osteoporosis and threshold for treatment (Dequeker, 1997).

The Saudi Osteoporosis Society has taken on the mission of providing evidence - based osteoporosis learning to health care providers through the organization of annual courses and conferences. The clinical decision to treat or not treat osteopenia mandates patients using the World Health Organization's Fracture Risk Assessment Tool (FRAX) (Dequeker, 1997).

Osteoporosis remains a major global public health concern. In Saudi Arabia, osteoporosis is a serious issue, with the kingdom's population of $1,461,401$ aged 50 or more, approximately 8,768 suffer from femoral fractures each year, costing yearly 1.14 billion in health care cost (Alwahhabi, 2015). In women over 45 years of age osteoporosis accounts for more days spent in hospital than many other diseases, including diabetes and breast cancer (AlHemyari Sabaa et al., 2018). Rational: A careful literature search found that no study was done in Jazan University to assess university students' knowledge about osteoporosis. This study is aimed to assess knowledge, attitude, and practices of osteoporosis risk factors among Jazan University students.

\section{Materials and Methods}

This study was conducted at Jazan University in Jizan region that lies in the southwestern corner of KSA.

Study design: A cross-sectional descriptive type of observational epidemiologic studies was carried out along three months duration, February to the end of April 2019.

Study population: Jazan University students (females and males) aged 18-30 years

Sampling technique: a stratified multistage cluster random sampling was done through a series of clusters. Jazan University was subdivided into main 3 sectors (health, science and art), then three colleges of its male and female sections ( 3 male and 3 female) were chosen randomly. The colleges are stratified by gender into two strata, the sample was chosen as a percent proportion with the females and male as one cluster for each.

Sample size: a total of 440 females and males of Jazan university students aged 18-30 years (Table1). The sample size calculated was carried out using Epi info- 7 at a 95\% confidence interval, $50 \%$ expected frequency, and accepted margin of error 5\%. The total number of students at Jazan University was 49960 students, the sample size was 384 to be adjusted to 400 , adding $10 \%$ of the calculated sample size to overcome the problems in data collection 40 , so the targeted number of students is estimated to be 440 students.

Data collection tools: data was collected by semistructured Arabic questionnaire composed of 4 parts:1) personal character: gender, educational level, social status, 2) knowledge about osteoporosis, 3) practices that predispose to osteoporosis and 4) practices to prevent osteoporosis.

Pilot study: a pilot study was done by distributing 20 questionnaires, the questionnaire was modified \& adjusted to the proposed time needed to respond according to the results. The results of the pilot study analysis were not included in results.

Data analysis: data analysis was done by the SPSS statistical program version 25. Qualitative data were expressed as number and percentages. Missed variables in some responses, the data are canceled from the study results.

Ethical consideration: ethical approval was obtained from Jizan University ethical committee and official approvals were taken from the university campus. Informed, verbal, and written consents were taken from all participants, and they were informed that the data collected will only be used for scientific purposes and they had the right to stay or withdrawal any time from the study. The confidentiality of the collected data are maintained.

\section{Results}

A total of 440 participants completed the survey questionnaire. The results showed that $50.5 \%$ of the study participants were females compared to $49.5 \%$ of them were males. Moreover, one-third of the study participants were studied in medical programs. In addition, around one-third also studied engineering or English programs. In terms of education level, it can be noted that approximately $60 \%$ of the study participants were in beginner level of their education (third year or less) compared to $40 \%$ of students were in the advance phase of their study (fourth year or more). The results also indicated that around two-thirds of students earned less than 10000 SAR monthly. Table 1 presents the sociodemographic characteristics of the study participants.

Table 1: Sociodemographic Characteristics of Participants $(n=440)$

\begin{tabular}{|c|l|l|}
\hline Characteristics & Frequency & Percentage \\
\hline Gender & & \\
Male & 219 & $49.7 \%$ \\
Female & 221 & $50.3 \%$ \\
\hline College (Program) & 146 & $31.8 \%$ \\
Medical & 146 & $31.8 \%$ \\
Engineering & 147 & $33.4 \%$ \\
English & & \\
Education Level & 63 & 14.3 \\
First year & 92 & 20.9 \\
Second year & 111 & 25.2 \\
Third year & 86 & 19.5 \\
Fourth year & 47 & 10.6 \\
Fifth year & 41 & 9.3 \\
Sixth year & & \\
\hline
\end{tabular}




\begin{tabular}{|c|l|l|}
\hline Monthly Income & & \\
$1000-5000$ SAR & 105 & $23.8 \%$ \\
$5000-10000$ SAR & 150 & $34.2 \%$ \\
$>10000$ SAR & 185 & $42.0 \%$ \\
\hline
\end{tabular}

The responses to individual knowledge statements about the risk factors of osteoporosis are listed in Table 2.

Table 2: Study Participants Attitude of Osteoporosis Risk Factors Prevention $(n=440)$

\begin{tabular}{|l|l|l|}
\hline Items & Agree & Disagree \\
\hline Osteoporosis is the loss of bone density & $402(91.3 \%)$ & $38(8.7 \%)$ \\
\hline Osteoporosis increases bone fracture & $352(80.0 \%)$ & $88(20 \%)$ \\
\hline Osteoporosis cause symptoms such as back pain & $330(75.0 \%)$ & $110(25.0 \%)$ \\
\hline $\begin{array}{l}\text { Obtaining a high bone mass during childhood gives protection against the occurrence of } \\
\text { osteoporosis in the future }\end{array}$ & $260(59.0 \%)$ & $180(41.0 \%)$ \\
\hline Women are more prone to osteoporosis & $250(56.8 \%)$ & $190(43.2 \%)$ \\
\hline Women with white skin are more prone to osteoporosis than others & $131(29.7 \%)$ & $309(70.1 \%)$ \\
\hline Older people are more prone to osteoporosis & $357(81.2 \%)$ & $82(18.8 \%)$ \\
\hline Most women aged 50 and above are at least twice as likely to break bones at least once before death & $240(54.5 \%)$ & $200(45.5 \%)$ \\
\hline The family history of osteoporosis contributes to osteoporosis & $168(38.1 \%)$ & $274(61.9 \%)$ \\
\hline Thyroid dysfunction may predispose to osteoporosis & $160(36.8 \%)$ & $280(63.6 \%)$ \\
\hline
\end{tabular}

Almost all study participants agreed with the definition of osteoporosis, which is the loss of bone density compared to only $9 \%$ of the students did not agree with the mentioned definition. In addition, $80 \%$ of the study participants identified bone fracture because of osteoporosis compared to $20 \%$ of students who expressed that osteoporosis does not increase the risk of bone fracture. When the study participants were asked about the symptoms accompanying osteoporosis, around two-third of the study participants indicated that back pain could be caused by osteoporosis. However, one quarter of the students thought osteoporosis has no symptoms.

It is apparent from the study participants responses, just more than half of them indicated that childhood bone mass density can prevent osteoporosis occurrence compared to $41 \%$ who believed that osteoporosis is not preventable. Additionally, 57\% of the study participants expressed that gender, namely, females, precipitates the incidence of osteoporosis. Similarly, the study participants suggested that white skin color could increase the risk of osteoporosis. The most interesting aspect of this table is that when a student was asked about the effect of age on the incidence of osteoporosis, $82 \%$ of students older age could increase the likelihood of osteoporosis. However, $62 \%$ of studies believed that there is no relationship between family history and incidence of osteoporosis. This negative finding is also echoed in another question when the study participants stated that thyroid dysfunction could increase the risk of osteoporosis.

Table 3: Study Participants Attitude of Osteoporosis Risk Factors Prevention $(n=440)$

\begin{tabular}{|l|l|l|}
\hline Subscale & Agree & Disagree \\
\hline Exposure to falls is an important cause of osteoporosis & $173(39.3 \%)$ & $267(60.7 \%)$ \\
\hline Physical activity is useful for osteoporosis & $240(54.5 \%)$ & $200(45.7 \%)$ \\
\hline Drink two cups of milk daily protects against osteoporosis & $344(78.2 \%)$ & $96(21.8 \%)$ \\
\hline Drink energy drinks may be a cause of osteoporosis & $289(65.4 \%)$ & $153(34.6 \%)$ \\
\hline Smoking contributes to osteoporosis & $207(47.3 \%)$ & $233(52.7 \%)$ \\
\hline Weightlifting and hard work contribute to an increased chance of osteoporosis & $126(28.7 \%)$ & $314(71.3 \%)$ \\
\hline
\end{tabular}

The results, as shown in Table 3, indicate that the positive attitude the study participants showed regarding the risk factor prevention of osteoporosis are related to the consumption of an adequate amount of milk daily. Another favorable attitude towards osteoporosis prevention derived from the decrease the amount of energy drink which is recognized as a factor of osteoporosis. 55\% of respondents reflected that physical activity is another strategy could mitigate the occurrence of osteoporosis. Approximately, half of the study participants agreed that prevention of smoking could protect against osteoporosis.

From the proper practices applied to prevent the incidence of osteoporosis, it can be noted that eating diary product could prevent osteoporosis (85\%) compared to the least proportion (15\%) believed food type could not mitigate the incidence during the osteoporosis. In addition, one-third of the study participants demonstrated that exposure to the sun could prevent osteoporosis. Moreover, the effect of physical exercise on osteoporosis is unclear as around half of the study participants indicated that physical activity minimizes the incidence of osteoporosis, while $40 \%$ of students did not link between physical exercise and osteoporosis prevention. Interestingly, most of the study participants stated that calcium consumption and vitamin $\mathrm{D}$ could not prevent osteoporosis, as documented in Table 4,5.

Table 4: Study Participants Proper Practice Carried Out to Avoid Osteoporosis $(n=440)$

\begin{tabular}{|l|l|l|}
\hline Eat dairy products & $373(84.8 \%)$ & $67(15.2 \%)$ \\
\hline Exposure to the sun is sufficient daily & $276(62.7 \%)$ & $164(37.3 \%)$ \\
\hline Exercise physical activities & $262(59.5 \%)$ & $177(40.1 \%)$ \\
\hline No smoking & $360(81.8 \%)$ & $80(18.2 \%)$ \\
\hline Consumption of Calcium supplements and vitamin D. & $78(17.8 \%)$ & $362(82.2 \%)$ \\
\hline
\end{tabular}


Table 5: Relationships between of knowledge and participant characteristics

\begin{tabular}{|c|c|c|c|c|c|c|c|c|c|c|c|c|c|c|c|c|}
\hline \multirow[b]{2}{*}{ Subscale } & \multicolumn{2}{|c|}{ Gender } & \multirow[t]{2}{*}{$\chi^{2}$} & \multirow[t]{2}{*}{$\mathbf{p}$} & \multicolumn{2}{|c|}{ College } & \multirow[t]{2}{*}{$\chi^{2}$} & \multirow[t]{2}{*}{$\mathbf{p}$} & \multicolumn{2}{|c|}{$\begin{array}{l}\text { Education } \\
\text { level }\end{array}$} & \multirow[t]{2}{*}{$\chi^{2}$} & \multirow[t]{2}{*}{$\mathbf{p}$} & \multicolumn{2}{|c|}{$\begin{array}{l}\text { Monthly } \\
\text { Salary }\end{array}$} & \multirow[t]{2}{*}{$\chi^{2}$} & \multirow[t]{2}{*}{ p } \\
\hline & M & $\mathbf{F}$ & & & $\begin{array}{l}\text { Med } \\
\text { ical }\end{array}$ & $\begin{array}{l}\text { Non } \\
\text {-MD }\end{array}$ & & & $\begin{array}{l}\text { Begi } \\
\text { nner }\end{array}$ & $\begin{array}{l}\text { Adv } \\
\text { ance }\end{array}$ & & & $\begin{array}{l}<50 \\
00\end{array}$ & $\begin{array}{l}>50 \\
00\end{array}$ & & \\
\hline $\begin{array}{l}\text { Osteoporosis is the } \\
\text { loss of bone density } \\
\text { - Agree }\end{array}$ & 203 & 201 & 27.1 & 0.12 & 134 & 144 & 46.1 & 0.01 & 152 & 148 & 5.45 & 0.14 & 110 & 125 & 3.87 & 0.28 \\
\hline $\begin{array}{l}\text { Osteoporosis } \\
\text { increases bone } \\
\text { fracture - Agree }\end{array}$ & 159 & 195 & 24.4 & 0.01 & 87 & 110 & 23.1 & 0.02 & 178 & 169 & 6.25 & 0.41 & 128 & 134 & 2.14 & 0.35 \\
\hline $\begin{array}{l}\text { Osteoporosis cause } \\
\text { symptoms such as } \\
\text { back pain - Agree }\end{array}$ & 179 & 151 & 19.2 & 0.01 & 84 & 78 & $\begin{array}{l}10.8 \\
7\end{array}$ & 0.32 & 110 & 109 & 10.3 & 0.54 & 194 & 157 & 3.4 & 0.74 \\
\hline $\begin{array}{l}\text { Obtaining a high } \\
\text { bone mass during } \\
\text { childhood gives } \\
\text { protection against } \\
\text { the occurrence of } \\
\text { osteoporosis in the } \\
\text { future - Agree }\end{array}$ & 152 & 110 & 18.4 & 0.01 & 94 & 86 & $\begin{array}{l}11.6 \\
7\end{array}$ & 1.25 & 110 & 147 & 7.14 & 0.24 & 102 & 97 & 4.65 & 0.04 \\
\hline $\begin{array}{l}\text { Women are more } \\
\text { prone to } \\
\text { osteoporosis - Agree }\end{array}$ & 108 & 144 & 13.3 & 0.02 & 122 & 110 & 7.54 & 0.34 & 117 & 108 & 4.36 & 0.34 & 115 & 89 & 3.54 & 0.02 \\
\hline $\begin{array}{l}\text { Women with white } \\
\text { skin are more prone } \\
\text { to osteoporosis than } \\
\text { others - Agree }\end{array}$ & 85 & 48 & 18.1 & 0.01 & 97 & 78 & 6.54 & 0.30 & 118 & 122 & 7.25 & 0.74 & 107 & 110 & 4.65 & 0.12 \\
\hline $\begin{array}{l}\text { Older people are } \\
\text { more prone to } \\
\text { osteoporosis - Agree }\end{array}$ & 181 & 178 & 4.33 & 0.11 & 105 & 103 & 4.21 & 0.24 & 98 & 89 & 5.37 & 0.34 & 89 & 90 & 3.87 & 0.34 \\
\hline $\begin{array}{l}\text { Most women aged } \\
50 \text { and above are at } \\
\text { least twice as likely } \\
\text { to break bones at } \\
\text { least once before } \\
\text { death - Agree }\end{array}$ & 120 & 122 & 2.34 & 0.23 & 78 & 69 & 3.78 & 0.34 & 107 & 110 & 4.85 & 0.25 & 75 & 82 & 6.78 & 0.74 \\
\hline $\begin{array}{l}\text { The family history } \\
\text { of osteoporosis } \\
\text { contributes to } \\
\text { osteoporosis - Agree }\end{array}$ & 120 & 122 & 2.4 & 0.2 & 107 & 110 & 8.65 & 0.59 & 118 & 107 & 6.41 & 0.47 & 68 & 73 & 9.25 & 0.35 \\
\hline $\begin{array}{l}\text { Thyroid dysfunction } \\
\text { may predispose to } \\
\text { osteoporosis - Agree }\end{array}$ & 73 & 95 & 5.4 & 0.07 & 120 & 118 & 6.54 & 0.25 & 98 & 104 & 8.54 & 0.85 & 72 & 81 & 6.78 & 0.24 \\
\hline
\end{tabular}

\section{Discussion}

Osteoporosis is the global health concern, and it is commonly seen among elderly people (Al-Hemyari et al., 2018). The university student constitutes the largest proportion of any community. Therefore that enhancing student knowledge, attitudes, and practices towards osteoporosis minimizes the risk of the problem. This study examines the university student's knowledge, attitude, and practices of osteoporosis risk factors in Jazan. The results revealed that the majority of the study participants were informed about the osteoporosis risk factors (Mahdaviazad et al., 2018).

Among the targeted population, $91 \%$ recognized the proper definition of osteoporosis. Our study revealed that most students had good knowledge regarding the complications of osteoporosis such as bone fracture and back pain. This is contrasted to a study conducted by (Tripathi et al., 2019) in King Saud University that showed the limited knowledge regarding osteoporosis among the included students. This difference could be explained by the difference in students' colleges as our study included medical students who were stipulated to have knowledge about osteoporosis. Indeed, student discipline was associated with higher levels of knowledge. In this study, most participants were able to identify calcium-rich food such as sardines and broccoli. This founding is supported by the findings from the study conducted by (Khired et al., 2021), in which only $48 \%$ of middle-aged and older Saudi women could correctly recognize these foods.

Additionally, the study participants identified advanced age as the main risk factor of osteoporosis. The study participants $81 \%$ stated that age is linked to the incidence of osteoporosis. This result is supported by those reported in a study of (Tripathi et al., 2019) indicated that elderly people (aged more than 50 years) increased the risk of osteoporosis by $30 \%$. Similarly, the study participants agreed that gender, namely, females, is a higher risk of having osteoporosis. Comparison of the findings with those of other studies confirms that almost $69 \%$ of participants were aware of women's susceptibility towards osteoporosis compared to men. 
The current study findings reiterated that family history is another factor which could increase the risk of osteoporosis. This result is supported by (Alharthi, 2018) who recruited medical interns' students $(n=440)$ and reported that $79 \%$ of them stated that family history is the main predisposing factor of osteoporosis.

In terms of the study participants attitudes towards osteoporosis, the study results demonstrated that the study participants had favorable attitudes towards osteoporosis prevention such as physical exercise, exposure to the sun, dietary intake and smoking prevention. These results corroborate the findings of a great deal of previous work in adopting various attitudes to prevent the incidence of osteoporosis. In a study conducted by (Alghunaim et al., 2016) who examined the attitudes of 419 medical interns showed positive attitudes towards osteoporosis prevention by stopping alcohol consumption, smoking cessation, and consuming health diet.

\section{Strengths and Limitations}

In this section, the strengths and limitations of the study are presented.

\section{Strengths}

To the best of our knowledge, this is one of a few studies conducted to assess a university student's knowledge and attitudes towards osteoporosis. The main study strength is that the study participants are representing by various programs (medical versus non-medical). A strength of this research is that the sample size is large, which increases the likelihood of generalizability.

Although this study is high-quality qualitative study, it has several limitations, the study participants were recruited from one site. On the other hand, we should be aware that the sample studied cannot be representative of the reference population, and this can evidently affect the generalization of the results.

\section{Conclusion}

In conclusion, adequate knowledge about osteoporosis was reported among university students in the study, particularly those regarding risk factors. This translated into high attitude and practice scores. Indeed, accurate information about the risks of osteoporosis is important because awareness may improve prevention behaviors, including nutrition and physical activity.

\section{Ethics approval and consent to participate}

This work has approved by Standing Committee for scientific Research Ethics-Jazan University (HAPO-10-Z-001) Reference No.: REC40/3/087 on 16 May 2019.

\section{List of abbreviations}

KSA: Kingdom of Saudi Arabia.

NUH: National Institutes of Health,

BMI: Body mass index,

DEXA: Bone density scan,

FDA: US Food and Drug Administration (FDA),

FRAX: Fracture Risk Assessment Tool,

BMD: Bone mineral density,

US: United States,

SPSS: Statistical Package of Social Software

\section{Data Availability}

The data used in this study are available and will be provided by the corresponding author on a reasonable request.

\section{Conflicts of Interest}

The authors have no personal or financial conflicts of interest to disclose.

\section{Funding Statement}

This research received no external funding.

\section{Authors' contributions}

Conceptualization, $\mathrm{MH}$ and $\mathrm{MM}$; writing-original draft, $\mathrm{MH}$; Methodology and Validation, MH,AD; Writing-Review and Editing, ZK , MM , MH , H.H ; All authors have contributed to data collection, Data Analysis M.H , H.H. Z.K and ME conceived and designed the study, provide research materials and final revision, and provide logistical support.All authors have read and agreed to the published version of the manuscript

\section{Acknowledgments}

The authors acknowledge Fatima Alahdal for assistance in preparing and writing the proposal.

\section{References}

[1] Sozen T, Ozisik L, Calik Basaran N. An overview and management of osteoporosis. Eur $\mathrm{J}$ Rheumatol. 2017;4(1):46-56.

[2] Sadat-Ali M, Al-Habdan IM, Al-Turki HA, Azam MQ. An epidemiological analysis of the incidence of osteoporosis and osteoporosis-related fractures among the Saudi Arabian population. Ann Saudi Med. 2012;32(6):637-41.

[3] Dequeker J. Overview of osteoporosis treatment. Br J Rheumatol. 1997;36(SUPPL. 1):5-9.

[4] WHO. Who Scientific Group on the Assessment of Osteoporosis At Primary Health. WHO Sci Gr Assess osteoprosis Prim Heal care Lev [Internet]. 2007; (May 2004):1-17. Available from: http://www.who.int/chp/topics/Osteoporosis.pdf

[5] Asomaning K, Bertone-Johnson ER, Nasca PC, Hooven F, Pekow PS. The association between body mass index and osteoporosis in patients referred for a bone mineral density examination. J Women's Heal. 2006;15(9):102834.

[6] Pouresmaeili F, Kamalidehghan B, Kamarehei M, Goh YM. Therapeutics and Clinical Risk Management Dovepress A comprehensive overview on osteoporosis and its risk factors. Ther Clin Risk Manag [Internet]. 2018;14:2029-49. Available from: http://dx.doi.org/10.2147/TCRM.S138000

[7] Alwahhabi BK. Osteoporosis in Saudi Arabia: Are we doing enough? Saudi Med J. 2015;36(10):1149-50.

[8] 8., et al. Knowledge, Attitude and Practices Towards Osteoporosis Among Saudi Population in Taif City. Int J Adv Res. 2016;4(11):2261-71. 
[9] Al-Hemyari SS, Jairoun AA, Jairoun MA, Metwali Z, Maymoun N. Assessment of knowledge, attitude and practice (KAP) of osteoporosis and its predictors among university students: Cross sectional study, UAE. J Adv Pharm Educ Res. 2018;8(3):43-8.

[10] Mahdaviazad H, Keshtkar V, Emami MJ. Osteoporosis guideline awareness among Iranian family physicians: Results of a knowledge, attitudes, and practices survey. Prim Heal Care Res Dev. 2018;19(5):485-91.

[11] Tripathi R, Makeen HA, Albarraq AA, Meraya AM, Tripathi $\mathrm{P}$, Faroug $\mathrm{H}$, et al. Knowledge, attitude and practice about osteoporosis in south-western Saudi Arabia: a cross-sectional survey. Int J Heal Promot Educ [Internet]. 2019;57(1):13-22. Available from: https://doi.org/10.1080/14635240.2018.1538809

[12] Khired ZA, El-Akabawy G, Alsebail RA, Alotaibi AE, Alblowi NS, Albalawi HK, et al.: Osteoporosis knowledge, attitudes, and practices among female Princess Nourah University students in Riyadh, Saudi Arabia (Archives of Osteoporosis, (2021), 16, 1, (1), 10.1007/s11657-020-00865-7). Arch Osteoporos. 2021;16(1):11657.

[13] Alharthi AS. Awareness of Osteoporosis among Saudi Population in Saudi Arabia Especially Taif Governorate. Egypt J Hosp Med. 2018;70(5):850-4.

[14] Alghunaim AAA, Alduraiee YSD, Almogbel HAS, Almujaydil AAA, Aldhuwyan ASH, Aldhuwyan H, et al.
Awareness of Osteoporosis Among Saudi Population in Saudi Arabia Especially Qassim Region. Int J Acad Sci Res [Internet]. 2016;4(4):2272-6446. Available from: www.ijasrjournal.org

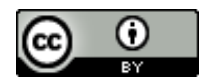

Open Access This article is licensed under a Creative Commons Attribution 4.0 International License, which permits use, sharing, adaptation, distribution and reproduction in any medium or format, as long as you give appropriate credit to the original author(s) and the source, provide a link to the Creative Commons license, and indicate if changes were made. The images or other third party material in this article are included in the article's Creative Commons license, unless indicated otherwise in a credit line to the material. If material is not included in the article's Creative Commons license and your intended use is not permitted by statutory regulation or exceeds the permitted use, you will need to obtain permission directly from the copyright holder. To view a copy of this license, visit https://creativecommons.org/licenses/by/4.0/.

(C) The Author(s) 2021 